\title{
Revista de Antropologia, a marca da tradição
}

\author{
Paula M ontero \\ Professora titular do D epartamento de Antropologia - USP
}

\begin{abstract}
RESU M 0 : Este breve ensaio se propõe a lançar um olhar retrospectivo para a década de 90 e avaliar os rumos da Revista de Antropol ogia, suas escolhas, bem como analisar o modo como ela veiculou, nesse período, as tendências teóricas e temáticas de nossa disciplina. Enfatiza o papel histórico deste periódico na interlocução intelectual de âmbito nacional, e os dilemas queessa linha editorial enfrenta em uma conjuntura marcada pela multiplicação de revistas regionais. Além disso, procura avaliar como, em comparação com outros periódicos, a Revista de Antropologia enfrenta (ou não) os desafios colocados pelo atual processo de internacional ização da disciplina .
\end{abstract}

PALAVRAS-CH AVE: história da antropologia, teoria antropológica.

Com a edição deste volume, a Revista de Antropologia celebra meio sé culo de existência. $\mathrm{N}$ ão é um feito de pouca monta para uma publicação acadêmica brasileira. Peridiocidade, padronização elongevidade foram alguns dos fantasmas que sempre acompanharam esse tipo de empreendimento. Podemos afirmar, pois, sem acanhamento, que em seus 50 anos de vida a Revista de Antropologia fundou uma tradição.

$\mathrm{H}$ á dez anos, tive a oportunidade de comemorar, em apresentação do número 36 da revista, a passagem de seu aniversário de 40 anos. Assinalara, na época, queela entrava, então, em sua terceira fase, quando 0 
D epartamento de Antropologia assume, em 1990, a responsabilidade por sua publicação e designa uma nova Comissão Editorial. O s 22 volumes publicados nesse período dão a medida de sua estabilidade e maturidade intel ectual. Embora seja ainda muito cedo para esboçarmos um balanço mais conseqüente desta terceira fase, acho que vale a pena ol har retrospectivamente para a década que se passou e avaliar seus rumos e escol has, as imagens e tendências de nossa disciplina que ela veiculou.

Se considerarmos a vocação histórica da Revista de Antropologia para a divulgação da pesquisa em âmbito nacional - uma vez que em 1956 torna-se a publicação oficial da recém-fundada Associação Brasileira de Antropologia (ABA) e de 1959 a 1968 da Associação Brasileira de Sociologia - , pode-se perceber que ela ainda mantém claramente este perfil. O s mais de cem artigos publicados ao longo da década apresentam a contribuição de autores e instituições de todo o país. Esse fato é particularmente interessante quando se considera que a $A B A$ fundou sua publicação oficial - o Anuário Antropológico - na década de 1970. E mais ainda: em seu balanço do perfil do Anuário na década de 1980 (1986-1996), Alcida Ramos observa que 45\% de sua produção é oriunda da própria Universidade de Braślia, onde o periódico é editado, e o restante se distribui por outros seis estados da Federação. N esta última década, quando passou a ser publicada pelo $D$ epartamento, a Revista de Antropologia (1991-2002) recebeu a contribuição de pelos menos 12 estados e concentrou apenas 19\% de seus artigos em pesquisadores (alunos e professores) do Programa de Pós-G raduação.

Essa vocação para uma interlocução intelectual de âmbito nacional é uma característica própria da Revista de Antropologia, que apenas uma política editorial firme consciente será capaz de manter no futuro próximo. A multiplicação de Programas de Pós-G raduação e de núcleos de pesquisa por todo o país tende a estimular a criação de inúmeras revistas regionais, freqüentemente ${ }^{1}$ mais voltadas para a produção local. Embo- 
ra não se tenha nenhum levantamento sistemático a respeito, se cada novo Programa de Pós-G raduação e curso de Antropologia criassem sua própria revista teríamos em um curtíssimo espaço de tempo pelo menos uma dezena de periódicos diferentes circulando na área. Parece-me difícil que viéssemos a ter uma produção em pesquisa compatível com esses grandes números. Além disso, paradoxalmente, se por uma lado, essa expansão aponta para um dinamismo crescente da produção disciplinar, por outro, implica uma dispersão do conhecimento que dificulta a consolidação de um novo patamar teórico do campo.

M as para melhor caracterizar o perfil da Revista de Antropologia parece-nos que seria interessante compará-la com outros dois periódicos mais recentemente publicados, a partir de meados da década de 1990, por outros importantes centros de pós-graduação do país: a revista M ana do M useu Nacional do Rio de Janeiro e a H orizontes Antropológicos da UFRGS.

No que diz respeito ao perfil dos autores dos artigos publicados, enquanto a Revista deAntropologia se define por seu caráter nacional, reservando apenas $11 \%$ de seu espaço para autores de fora do país, as duas outras publicações se caracterizam por uma importante contribuição internacional ao lado de forte presença de pesquisadores da própria instituição. N o caso da M ana cerca de $80 \%$ dos autores se dividem entre pesquisadores e alunos do M useu N acional e estrangeiros (predominantemente ingleses e franceses); em H orizontes Antropológicos, embora sua linha editorial privilegie números temáticos, o que certamente repercute na distribuição dos autores, temos um perfil nitidamente regional, no que tange aos autores brasileiros (principalmente do Rio Grande do Sul e de Santa C atarina), e forte presença de pesquisadores estrangeiros: europeus (principalmente franceses) elatino-americanos (sobretudo argentinos).

Seria interessante observarmos com mais profundidade os nexos e a direção dessas articulações entre a pesquisa nacional e a estrangeira. 
Certamente, o significado dessas redes de troca intelectual deve variar muito em função do período em que se estabelecem e dos agentes que colocam em jogo. Vimosque, por ter sido fundada pelo professor Egon Schaden, a Revista de Antropologia foi marcada, em sua primeira fase, pela forte presença de pensadores alemães. $\mathrm{No}$ entanto, à medida que foi se configurando como instrumento articulador da pesquisa nacional, os autores estrangeiros foram se tornando progressivamente minoritários. 0 Anuário Antropológico, tal vez por também ter desempenhado esse papel a partir da década de 1970, publica poucos trabalhos de autores estrangeiros e, mesmo assim, sem muita sistematicidade ou perfil nítido de concentração regional e/ ou temática.

Em contraposição, as publicações mais recentes a que me referi anteriormente destinam quase $40 \%$ de seu espaço para autores não-brasileiros. Seria essa proporção um indício significativo de um novo tipo de inserção progressiva da antropologia brasileira no cenário internacional?

É difícil responder a essa questão uma vez que ela depende de inúmeras variáveis para as quais não dispomos de informação suficiente: oscilações das políticas de estímulo à formação de pesquisadores no exterior, conexões e trajetórias dos grupos de pesquisa, estado do conhecimento de diferentes "realidades nacionais", problemáticas mais ou menos internacionalizadas e/ ou consolidadas no país etc. Ainda assim, até onde se pode ver a partir dos casos citados, fica mais ou menos claro uma conexão Cone-Sul, no caso da H orizontes Antropológicos, com predomínio da Argentina e de relações preferenciais com diversas instituições de ensino da França. Temas como relações interétnicas, turismo, diferenças culturais estimulam comparações entre experiências de diversos países, tal como Argentina, Canadá, Japão, M acau etc. No caso da revista $M$ ana, essas conexões se realizam, sobretudo, em torno da etnologia indígena que tem na Amazônia um vasto campo de pesquisa de interesse internacional. Autores como Joanna $O$ vering, $M$ arshall 
Sahlins, Peter Gow, Stephen H ugh-Jones entre outros, têm marcado a interlocução teórica nesse campo com os autores brasileiros.

A internacionalização das ciências humanas é uma questão atual e bastante importante que mereceria reflexão mais detal hada. Alguns autores chamam a atenção para os deslocamentos teóricos da disciplina antropológica provocados pela ascensão de autores de países periféricos (em particular antigos países coloniais tais como Índia, alguns países da África etc.) às cátedras das grandes universidades européias e americanas: a dita "antropologia pós-moderna" resultaria da crítica teórica à herança colonial da antropologia elaborada a partir dos países centrais. $N$ esse sentido a tradicional divisão do trabalho intelectual entre centro e periferia - na qual o primeiro produz teoria e o outro a adapta às condições locais - seria mantida em novos termos. Roberto C ardoso de 0 liveira (1993) caracteriza essa antropologia periférica (a que se faz em países que não testemunharam a emergência da disciplina em seu território) em termos de seu compromisso com a construção da nação. Assim, esse tipo de antropologia, que se desenvolve de maneira particular na América Latina, procura adequar aos dilemas da nacionalidade os paradigmas teóricos desenvolvidos nos países centrais; assim fazendo, este "estilo antropológico" no dizer de Cardoso de O liveira, que se caracteriza por sua compul são pela análise da dimensão política das relações entre índios e nacionais, produz apenas um novo léxico para a disciplina, não afetando sua sintaxe hegemônica (p. 24). Se for esse o caso, teríamos apenas a reiteração do padrão de ciências sociais já caracterizado, há mais de uma década, por Fábio W. Reis (1991, p. 30) M as seriam esses os termos que, ainda atualmente, caracterizam a interlocução internacional da antropologia brasileira tal como ela se apresenta nas revistas que mencionamos?

É difícil responder a essa questão em termos gerais. Talvez esse debate tenha se desenvolvido com particular densidade no campo da 
etnologia indígena. Em sua avaliação da contribuição do indigenismo para o desenvolvimento do pensamento antropológico brasileiro, $\mathrm{Vi}$ veiros de Castro critica seus "títulos de brasilidade": segundo ele, a etnologia seria ainda atualmente a área preferencial de atuação de pesquisadores estrangeiros, enquanto os brasileiros se voltariam basicamente para a análise das situações de contato interétnico (1999, p. 157). M as que seria o brasilei ro dessa etnologia brasileira, pergunta-se ele? Trocando em miúdos, seu traço distintivo seria seu indigenismo, ou seja, seu engajamento político na defesa das populações indígenas. N esse sentido, a caracterização estilística da etnol ogia brasileira estaria, na apreciação de Viveiros, em sua preocupação em enquadrar a "questão indígena" nos termos da consolidação de um Estado nacional.

Em contraposição a essa vertente, o autor sugere que os estudos recentes sobre os sistemas sociocosmológicos das sociedades indígenas amazônicas anteciparam questões, tais como corporalidade e relações entre mito, ritual e história, que tiveram significativo impacto teórico nos paradigmas da disciplina. Para ele, a verdadeira contribuição teórica que a antropologia nacional pode trazer para a disciplina em geral dependerá de nossa capacidade de "meter a col her na sopa metropolitana" (p. 177).

No que diz respeito ao modo como a interlocução com autores nãobrasileiros se expressa no outro periódico citado acima, a revista $\mathrm{H}$ orizontes Antropológicos, temas como identidade e etnicidade, inspirados na perspectiva de Frédrick Barth e na temática do transnacionalismo suscitada pelos movimentos migratórios internacionais, estimulam estudos comparativos entre diversas situações geográficas particulares. Trabalhos sobre o modo como brasileiros mantêm sua identidade no Japão, como palestinos o fazem no Brasil ou portugueses no Canadá, por exemplo, estão reunidos em um volume sobre relações interétnicas. Assim, mais do que uma interlocução teórica em torno de conceitos e 
novas questões, a expectativa parece ser a de aproximar estudos pontuais que, quando visto em conjunto, poderiam autorizar generalizações mais abrangentes. $\mathrm{No}$ entanto, além de al gumas referências a autores da "globalização" tais como James Clifford, não se pode perceber a construção de um campo de investigação comum com tendências paradigmáticas definidas: assim como os brasileiros, os autores estrangeiros, originários das mais diversas instituições universitárias, têm com referência uma literatura marcadamente local. D esse modo, apesar da preocupação comum dos autores em torno dos avatares das identidades culturais em um mundo marcado por constantes fluxos de grupos étnicos e pela revalorização das tradições, é ainda muito cedo para que possamos delinear a natureza e o alcance desse tipo de diálogo com a produção internacional.

0 que dizer a respeito do perfil da Revista de Antropologia com relação a essa questão? Embora, como já observamos, a presença de autores estrangeiros em suas páginas, quando comparada aos outros periódicos, seja bastante marginal, ela se dá marcadamente no campo da etnologia indígena que cobre a maior parte dos artigos publicados na revista no decênio (em torno de 35\%). Autores muito importantes na revista $M$ ana tais como Peter $\mathrm{G}$ ow e Joanna $O$ vering, também reaparecem aqui, bem como na bibliografia dos artigos dos pesquisadores brasileiros sobre 0 tema. Assim, a interlocução internacional da revista se faz, no campo da etnologia, em moldes muito semelhantes aos da revista carioca certamente em razão de sua afinidade teórica e temática com os grupos de pesquisa paulistas e da prioridade dessa área nas duas publicações.

M as há um outro aspecto interessante que caracteriza o perfil da Re vista deAntropol ogia quando comparada a suas congêneres: na distribuição temática dos volumes ao longo da década percebe-se um expressivo e sistemático investimento na revisão e nos balanços teóricos de temas clássicos, bem como na história das idéias de nossa disciplina. Ao lado 
da análise da obra de autores clássicos e contemporâneos, tais como $M$ alinowski, N imuendaju, Pritchard eSahlins, vários artigos se ocupam de questões metodológicas e conceituais: reflexibilidade, objetividade, reciprocidade, trabalho de campo são objeto de escrutínio teórico em função da experiência acumulada pelas mais variadas formas de investigação antropológica. Temos, portanto, aqui um nítido esforço de, a partir do conhecimento acumulado em diversas áreas de pesquisa, fazer avançar as fronteiras da disciplina. N o entanto, apesar das reconhecidas virtudes e da necessidade desse esforço permanece inteiro o problema de sua interlocução com a produção internacional. A barreira da língua e a pouca circulação da revista nos fóruns internacionais tornam esses diálogos bastante restritos e, como diria Viveiros, enfatizam o fato de que a teoria estrangeira permanece "impavidamente al heia ao que se faz com seu nome e em seu nome" (1999).

$$
* * *
$$

Essas poucas e despretensiosas observações sobrea traj etória de nossa revista neste último decênio não estão, evidentemente, à altura da contribuição deste periódico para o amadurecimento da antropologia brasileira. $\mathrm{N}$ o entanto, mais do que enaltecer o passado, toda comemoração deve apontar para uma perspectiva de futuro.

É fato conhecido quea antropologia brasileira, quando comparada a de outras nações latino-americanas e mesmo al gumas européias, alcançou um expressivo grau de maturidade e relevância. Alguns países tais como a Argentina, certos países africanos e centro-europeus têm enviado regularmente seus estudantes para empreender estudos de pós-graduação em nossas instituições. 0 contexto atual de ampla circulação de pessoas e idéias nos obriga a pensar o papel eo al cance de um periódico como 0 nosso e avaliar o melhor caminho a seguir para garantir sua relevância. 
U m dos dilemas que devemos enfrentar éo da visibilidadeinternacional de nossa produção. Com relação a esse problema, parecenos que um importante passo foi dado: a inclusão da Revista de Antropologia no Scientific Electronic Librarieon Line(Scielo). Biblioteca virtual quehoje reúne cerca de 115 periódicos, entre os quais 11 da área de ciências humanas, ela disponibiliza coleções completas de periódicos desde 1997. Assim, apesar da barreira da língua, os resumos em inglês tornam disponível, para qualquer leitor interessado, os artigos publicados na revista.

$\mathrm{N}$ ão temos val ores de referência para avaliarmos o impacto dessa inovação sobre a acessibilidade da produção brasileira. $M$ as, pelas cifras fornecidas pelo próprio Scielo, se pode ver que, entre 1997 e 2002, pelo menos 105 mil pessoas consultaram os índices dos artigos disponíveis nos 12 volumes on line. Além disso, entre os cinco artigos mais requisitados, foram registrados entre mil e 1.500 downloads. Embora não se tenha informação sobre o perfil dessa demanda, parece-me difícil que essas cifras de leitores pudessem ser al cançadas por meio da distribuição em papel ou de consultas em bibliotecas. Trinta e seis artigos tiveram mais de 500 leitores: considerando-se que a tiragem da revista é de 500 números (e que uma cifra expressiva de unidades não é distribuída), 0 público on line esgotou o correspondente à edição de seis volumes completos nestes últimos seis anos.

$M$ ais complicado do que a questão da penetração da revista é o problema da interlocução com a produção internacional. É conhecido o fato de que os pesquisadores brasileiros, de um modo geral, publicam muito pouco em revistas estrangeiras. 0 significado desse dado não é óbvio: ele não mede, necessariamente, a qualidade ea relevância do que se faz por aqui. Ao mesmo tempo, se nos perguntarmos o que nosso público quer ler nas revistas que publicamos, perceberemos que os autores estrangeiros não são tampouco os mais requisitados: na Revista de Antropologia o primeiro não-brasileiro aparece na 39a posição com me- 
nos de 500 pedidos de usuários - trata-se de um artigo teórico sobre o individualismo em Luis D umont; quanto à revista $M$ ana que confere, como vimos, um espaço muitíssimo mais importante para autores estrangeiros, os dados sobre a leitura são também interessantes: embora Sahlins apareça em primeiro lugar, com mais de 2.000 leitores, dos 20 artigos com mais de 500 consultas apenas seis são autores estrangeiros. Portanto, não é exatamente a divulgação do que se faz lá fora que parece motivar os leitores dessas revistas.

U m olhar mais atento sobre a lista dos artigos mais lidos indica que, em ambos os periódicos, o público busca artigos teóricos que tratam da obra e de aspectos conceituais e metodológicos de autores clássicos tenham sido eles escritos por estrangeiros ou não.

C omo interpretar esse fato? Por que os artigos mais voltados para a divulgação da pesquisa propriamente dita não são tão procurados ou 0 são de maneira mais dispersa e pontual? Impossível responder a essa questão sem dados a respeito de nosso público leitor. $M$ as podemos afirmar, sem muito risco de erro, que se trata de um público universitário composto de estudantes de programas de pós-graduação no país e cada vez mais no exterior (principalmente América Latina, uma vez que 0 Scielo já faz conexão com outros países do continente). Se isso for verdade, nosso periódico parece servir sobretudo como instrumento na formação avançada de pesquisadores do que como espaço para o debate paradigmático da disciplina. Evidentemente isso não é um problema, mas deixa em aberto a questão da necessária interlocução com o que se faz lá fora. Afinal, à medida que o Brasil muda suas relações com o mundo, deve ser capaz de pensar determinados problemas que ultrapassam suas fronteiras.

Esse me parece ser um dos grandes desafios para a próxima década da Revista de Antropologia. Consolidar o conhecimento nas mais importantes áreas da pesquisa no Brasil, pôr à prova os grandes teoremas a 
partir das especificidades de nossa relação com o mundo - que deve ser minuciosamente investigada e conhecida -, decifrar as implicações e pressupostos das explicações comumente aceitas e seu modo de construir problemas são, talvez, tarefas inerentes a nossa atividade, mas para as quais a Revista de Antropologia poderá contribuir imensamente assinalando os caminhos, as posições já conquistadas e aquilo que há de vir.

\section{N ota}

1 A penas como exemplo dessa efervescência, podemos citar a criação dos Cadernos de Antropologia e Imagem, do Programa de Pós-G raduação da UERJ, de a revista M ana, do Programa de Pós-Graduação do M useu N acional em 1995, de A Ilha, do Programa de Pós-G raduação da U FSC em 2001, de H orizontes Antropológicos, do Programa de Pós-Graduação da U FRGS etc.

\section{Bibliografia}

CARDOSO DE OLIVEIRA, R.

19930 movimento dos conceitos na Antropologia, Revista de Antropologia, n. 36.

REIS, F. W.

1991a O tabelião ea lupa: teoria e método generalizante e idiografia no contexto brasileiro, Revista Brasileira de Ciências Sociais, n. 16, ano 6.

1991b "Paris pensa o mundo, São Paulo pensa o Brasil, R cife pensa o N ordeste".

VIVEIROS DE CASTRO, E.

1999 Etnologia Brasileira, in 0 que ler na ciência social brasileira, n. 1 São Paulo, Anpocs. 
ABST RACT: This brief essay consists of a retrospective glance at the decade of the 1990s. D irections which were taken and choices made in respect to the Revista de Antropologia are evaluated. So also, the ways in which this anthropological journal articulated, during the decade, the theoretical and thematic tendencies of our discipline are analyzed. Emphasis is given to its historical role in fostering intellectual discourse and dialogue at a national level, as well as to the dilemmas, of an editorial nature, faced by this particular periodical during a period characterized by the proliferation of regional journals. Furthermore, an evaluation is made of the ways in which the Revista de Antropologia, in comparison with other periodicals, is facing (or not) the challenges posed by current processes of internationalization of the discipline.

KEY-W ORD S: H istory of Anthropology, anthropological theory.

Recebido em dezembro de 2003. 